\title{
Leitura: êxitos e insucessos
}

Alba Maria PERFEITO

Universidade Estadual de Londrina

Palavras-chave: leitura, co-produção textual, êxito, insucesso.

Resumo: Este artigo focaliza questões relativas à leitura como um processo de co-produção textual. Nesse sentido, analisa o êxito e o insucesso do leitor.

Abstract: This article analyses issues related to the reading as a process of textual co-production. In order to that, focalizes the successful and the unsuccessful reader.

Resumen: Este artículo enfoca cuestiones relativas a la lectura como un proceso de coproducción textual. En ese sentido, analiza el éxito e el poco éxito de lo lector.

\section{Introdução}

O artigo em tela discute a relação sujeito-leitor e o texto, partindo dos pressupostos de que a leitura é um espaço ampliador de constituição da subjetividade e, ainda, de que é passível de insucesso. Nesse sentido, concebe a leitura como instauradora de diálogos na dimensão espáciotemporal, propiciando diferentes formas de ver, de avaliar o mundo e de (re) reconhecer o outro. Considera, também, o ato de ler uma transação entre a competência do leitor e a competência que o texto postula. (Eco, 1993) Entende, dessa forma, que, embora o autor movimente recursos expressivos na tentativa de interagir com o leitor, a efetivação da leitura depende de fatores lingüísticos e não-lingüísticos: o texto é uma 
potencialidade significativa, mas necessita da mobilização do universo de conhecimento do outro - o leitor - para ser atualizado.

\section{E como o leitor se institui no texto?}

Dell'Isola (1996) ressalta que a leitura como produção ativa se realiza quando dá ao texto uma nova vida, provocando um processo criativo de compreensão e interpretação, tendo em vista o leitor, considerado coprodutor do texto. E, para que essa co-enunciação se realize, é preciso que se ative todo um processo sígnico, abrangente e complexo, que vai desde a percepção do texto pelos olhos e pelo cérebro, de movimentos inferenciais até a interpretação, entendida como a recriação do texto lido.

A autora defende que a leitura, como ato individual, é determinada pelas condições sociais, históricas, afetivas do leitor. Nesse contexto, é variável devido à incompletude textual, o que leva o leitor a preenchê-la, a seu modo, produzindo, do mesmo texto, leituras diferentes que podem variar, porque a relação leitor/mundo/contexto também pode sofrer mudanças $\mathrm{e}^{\text {" } . . .}$ as novas experiências pessoais interferem nas impressões que se têm sobre a realidade, sobre o modo de ver, de estar, de viver no mundo". (op. cit., p. 73).

Brandão (1997) corrobora essa concepção, enfatizando o fato de o texto ser marcado por sua inconclusão. É por meio do ato de leitura que sua incompletude é preenchida. O leitor é o outro que completa o texto, é o elemento ativo no processo de acabamento textual, fazendo o texto funcionar.

O trabalho de co-produção de sentidos, por intermédio da recriação do que é omitido e dos implícitos, do preenchimento de incompletudes, é assentado na interação sujeito-leitor e texto, em suas múltiplas possibilidades de interpretação. $O$ leitor, desse modo, situa-se entre $\mathrm{o}$ movimento de expansão e de filtragem de sentidos.

Nessa relação, é criado um significado global do texto, que não é aquele intencionado pelo autor nem o do leitor, mas o resultante do trabalho 
dialógico de ambos. Esse processo de reconstrução textual é realizado, porque o leitor mobiliza seus conhecimentos prévios (lingüísticos, textuais e de mundo), preenchendo as lacunas textuais, via pistas interpretativas, deixadas pelo autor. Tal enfoque põe em evidência que o ato de ler não se trata de um mero transporte das informações do texto à mente do leitor, de um decifrar de sinais, de repetição de saber, mas que o leitor, através de artefatos textuais, imprime sua interpretação, sua marca pessoal.

No processo de interação texto-leitor, a autora salienta que um texto bem formado (aquele que leva em consideração aspectos lingüísticos, semânticos e pragmáticos) traz em seu interior, desde o momento inicial, a preocupação com o seu destinatário, o qual se institui em duas instâncias: no nível pragmático e no nível semântico.

No nível pragmático, o texto, veiculando mensagens para "atingir" um destinatário, mobiliza estratégias facilitadoras para o processo comunicativo. Então, de acordo com a perspectiva bakhtiniana, o outro encontra-se presente no próprio movimento de produção textual, tanto pelo fato de o autor encaminhá-la para um público alvo, como pelo fato de o leitor participar do processo de comunicação social presente numa dada sociedade. Assim, caberia ao leitor mobilizar seu universo de conhecimentos, para dar sentido ao texto, recuperando a interdiscursividade (os diferentes modos de cultura de linguagem - as formações discursivas - que permeiam a produção textual).

No nível lingüistico-semântico, o texto é considerado uma potencialidade significativa, concretizada no momento da leitura, através de um leitor instituído no texto, capaz de reelaboração do próprio universo representado, partindo das indicações de pistas lingüísticas que lhe são fornecidas. É o movimento de leitura, o trabalho de construção realizado pelo leitor, que atualiza o texto. 


\section{Mas há insucesso de leitura?}

Umberto Eco (1993) defende que um texto pode ter mais de um sentido, mas isso não significa que possa admitir todos. Possenti (1991), ressaltando uma visão discursiva de leitura, admite ser possível haver leituras erradas. $\mathrm{O}$ autor justifica sua posição, no sentido de as línguas serem indeterminadas, exigindo, no processo de compreensão textual, de contribuições de aspectos verbais e não verbais. Tais aspectos portanto “... podem ser desconhecidos, em determinado momento por determinado leitor e permitir erro" (Posenti, 1991, p. 720).

Para Geraldi (1991), o texto não tem sentido fixo e único, mas o leitor não pode ser visto como categoria única no processo dialogal. Postula, também, a existência de lacunas textuais como algo inevitável. Essa incompletude é preenchida de forma diferenciada, em conseqüência de diferentes interpretações das estratégias de produção e pelo fato de o autor e de o leitor poderem pertencer a diferentes universos discursivos e a instâncias diferentes de uso lingüístico. Em virtude disso, não se deve considerar uma leitura privilegiada como única, mas não é possível se admitir qualquer leitura “...como se o texto não fosse condição necessária à leitura e como se neste o autor não mobilizasse recursos expressivos, em busca de uma leitura possível" (Geraldi, 1991, p. 112).

Em decorrência do exposto, o autor propõe a reconstrução da caminhada interpretativa do leitor, sobretudo do aluno-leitor no ensino fundamental e médio, a fim de que sejam descobertas quais variáveis sóciocultural-lingüísticas foram acionadas para o sujeito produzir sua leitura. Tal proposta é considerada, neste estudo, na análise de leituras bem e pouco ou mal sucedidas, por meio de paráfrases reprodutivas ${ }^{1}$, elaboradas

\footnotetext{
${ }^{1}$ Segundo Meserani (1995), diferente da reprodução - que é a transcrição do mesmo, a cópia -, a paráfrase reprodutiva, servindo de apoio à possibilidade de exercício intertextual, mostra como o texto original é compreendido e quais os modos de reproduzi-lo.
} 
pelos sujeitos R., 12 anos, e D., 13 anos, alunos de $5^{\text {a }}$ série de escola pública de periferia, na cidade de Londrina. ${ }^{2}$

Desse modo, os textos produzidos pelos sujeitos serão abordados em função do processo de retomada - modificação de sentidos (dos modos de dizer) do texto original, tendo em vista o acionamento de seus repertórios sócio-cultural-lingǘsticos, a partir de indicações das pistas textuais.

\section{Os êxitos na leitura}

O primeiro texto selecionado para exercício da paráfrase reprodutiva, Vera Vaca, ${ }^{3}$ configura sua narrativa, grosso modo, de maneira usual: apresentação da personagem e do seu conflito; tentativa de resolução e resolução do mesmo.

Os modos de contar da autora, a mistura criativa de variados modos de dizer, abordando, num só parágrafo, de forma enxuta e coloquial, temáticas engraçadas/sugestivas, é que tornam seus textos envolventes.

Para concretizar o efeito de visualização/comparação citado, subdividimos esse texto de Diléa Frate em seis organizadores dominantes:

- apresentação da personagem principal, de seu problema e de comentários sobre ele;

- evocação, justificada, do sentimento de Vera;

- apresentação da outra personagem, com a evocação de suas atitudes/intenções, e a caracterização dessas intenções;

- a concretização das intenções;

\footnotetext{
${ }^{2}$ A pesquisa, realizada em 1997, faz parte da tese de doutorado da autora (1999). Na elaboração desta atividade, os sujeitos, já familiarizados com o estudo e com a pesquisadora, ficaram à vontade para ler o texto e questionar termos não compreendidos contextualmente, porém não fizeram uso desse último recurso.

${ }^{3}$ Frate, Diléa. Histórias para acordar. São Paulo: Companhia das Letrinhas, 1996.
} 
- o acontecimento notável, entremeado pela apresentação/descrição de outra personagem e de comentários da narradora; - a resolução do conflito, iniciada por avaliação.

\begin{tabular}{|c|c|c|}
\hline TEXTO-FONTE & TEXTO DE R. & TEXTO DE D. \\
\hline $\begin{array}{l}\text { Vera era uma vaca com } \\
\text { um problema: não tinha } \\
\text { leite. Já pensaram que } \\
\text { drama deve ser isso para } \\
\text { uma vaca? }\end{array}$ & $\begin{array}{l}\text { Vera era uma vaca que } \\
\text { tinha um problema: não } \\
\text { tinha leite. } \\
\text { Já pensou que drama } \\
\text { seria uma vaca sem leite. }\end{array}$ & $\begin{array}{l}\text { Vera era uma vaca que } \\
\text { não tinha leite. } \\
\text { Imagine uma vaca sem } \\
\text { leite que drama. }\end{array}$ \\
\hline $\begin{array}{l}\text { Pois Vera, por causa da } \\
\text { falta de leite, tinha crises } \\
\text { de depressão. }\end{array}$ & A vaca muita, chateada. & Vera vivia triste. \\
\hline $\begin{array}{l}\text { Seu Manoel Verdureiro, } \\
\text { um homem muito } \\
\text { sensível, compreendeu a } \\
\text { situação de Vera. Não se } \\
\text { aproximou dela com o } \\
\text { baldinho e achou que } \\
\text { devia fazer algo para } \\
\text { alegrá-la. }\end{array}$ & $\begin{array}{l}\text { Conversou com Manuel, } \\
\text { seu dono. } \\
\text { Manuel queria muito } \\
\text { agradála. } \\
\end{array}$ & $\begin{array}{l}\text { Seu Manuel, o } \\
\text { fazendeiro decidiu } \\
\text { afastar o baldinho de } \\
\text { Vera e para alegrar Vera. }\end{array}$ \\
\hline $\begin{array}{l}\text { Chamou o Boi Barrica, } \\
\text { que providenciou uma } \\
\text { lindíssima festa de } \\
\text { bumba-meu boi. }\end{array}$ & $\begin{array}{l}\text { E ai então, boi Barrica } \\
\text { preparou, uma festa para } \\
\text { Vera. }\end{array}$ & $\begin{array}{l}\text { o boi Barrica fez a festa } \\
\text { chamada "bumba-meu- } \\
\text { boi". }\end{array}$ \\
\hline $\begin{array}{l}\text { Na festa Vera conheceu } \\
\text { Zebu, um boizão cinza } \\
\text { que era um gato. Logo } \\
\text { estavam dançando, logo } \\
\text { estavam namorando, } \\
\text { logo estavam se } \\
\text { beijando e, sabem como } \\
\text { são essas coisas... logo } \\
\text { estavam fazendo } \\
\text { bezerrinho. }\end{array}$ & $\begin{array}{l}\text { Lá na festa, Vera estava } \\
\text { muito feliz e até } \\
\text { arranjou, um namorado } \\
\text { que si chamava Zebu. } \\
\text { E ai então a vaca, teve } \\
\text { um bezerrinho que si } \\
\text { chamava Lucas. }\end{array}$ & $\begin{array}{l}\text { Na festa Vera conheceu } \\
\text { um boizerrão muito } \\
\text { gato que logo } \\
\text { começaram a dançar a se } \\
\text { abraçar, se beijar até } \\
\text { fazer o bezerrinho Ao o } \\
\text { bezerrinho que se } \\
\text { chama Lucas nascer } \\
\text { Vera e Zebu ficaram } \\
\text { felizes. }\end{array}$ \\
\hline \begin{tabular}{|l|} 
Não preciso nem dizer \\
que Vera sarou do seu \\
problema do leite: \\
amamentou o \\
bezerrinho Lucas até \\
virar bezerrão e ainda \\
sobrou muito leite para o \\
baldinho de seu Manoel. \\
\end{tabular} & $\begin{array}{l}\text { E não precisava, nem } \\
\text { dizer se a Vera sarou do } \\
\text { problema. E ai então a } \\
\text { Vera, alimentou o } \\
\text { bezerrinho até ficar um } \\
\text { bizerrão. } \\
\text { E até sobrou leite, no } \\
\text { baldinho para o Manuel. }\end{array}$ & $\begin{array}{l}\text { E Vera tinha leite para } \\
\text { amamentar Lucas e } \\
\text { sobrar para o baldinho } \\
\text { de seu Manuel. }\end{array}$ \\
\hline
\end{tabular}


R. inicia seu texto, utilizando o recurso da catáfora, tal qual feito pela autora, apenas encaixando uma oração adjetiva, que retira a concisão do enunciado original (Vera era uma vaca que tinha um problema: não tinha leite.).

Reproduz, então, quase literalmente, o comentário da autora sobre o problema de Vera (Já penson que drama seria uma vaca sem leite.),contudo não utiliza ponto de interrogação.

A seguir, no mesmo parágrafo, expõe uma atitude de Vera. Introduz essa ação da vaca, apresentando, num encaixe bem feito, a evocação dos sentimentos (A vaca muito, chateada conversou com Manuel, seu dono.). $\mathrm{R}$. infere ser seu Manoel o dono da vaca, numa operação interessante, via aposto. $\mathrm{O}$ fato de inferir a conversa entre a Vera e seu dono deve ter sido propiciado pelo contato com o mundo mágico dos contos infantis, das fábulas e ensejada pelo próprio texto lido - afinal, ali, os animais agem como seres humanos.

No parágrafo três, ele evoca intenções de Seu Manoel para agradá-la e não alegrá-la, como o original (Manuel queria muito agradala.). Introduzindo elementos de oralidade, ${ }^{4}$ apresenta o boi Barrica sem conexão com o verdureiro, na tentativa de resolver o problema de Vera (E ai então o boi Barrica preparou, uma festa par Vera.).

$\mathrm{O}$ acontecimento notável aparece no quarto parágrafo. R. apreende, de forma pertinente, os sentimentos de Vera, circunstancializando espacialmente o evento e fazendo uso da partícula de realce lá. Ainda, por meio do operador argumentativo até, orienta o leitor para o ápice da felicidade de Vera. Então nomeia seu namorado, via oração adjetiva desenvolvida, mas não o descreve (Lá na festa Vera, estava muito felize até arranjou, um namorado que si chamava Zebu.).

\footnotetext{
${ }^{4}$ Os elementos de oralidade no texto dos alunos, algumas vezes mencionados no artigo, dizem respeito aos seus modos de cultura de linguagem. Não se objetiva, aqui, avaliar a produção escrita dos mesmos.
} 
Introduz outro enunciado, usando novamente os marcadores de progressão E ai então, para colocar o clímax do acontecimento notável - o nascimento do bezerro. A seguir, nomeia-o, utilizando oração adjetiva desenvolvida. (E ai então a vaca, teve um bezerrinho, que si chamava Lucas.). No mesmo parágrafo retoma, de forma muito semelhante, o comentário do texto-fonte (E não precisava nem dizer se Vera sarou do problema.). E, mais uma vez, por intermédio de elementos coesivos de oralidade, apresenta uma parte do desfecho da história (E ai então a Vera, alimentou o bezerrinho até ficar um bižerrão.). Duas modificações lexicais são realizadas: o uso de amamentar por alimentar, e de virar por ficar.

Coloca, mais uma vez, o operador conclusivo até, no último parágrafo e aponta o restante do desfecho, numa espécie de coda, de forma semelhante à autora (E até sobrou leite, no baldinho para o Manuel.).

Enfim, o sujeito-leitor R. co-produz a história, colocando-se no mundo da ficção, mostrando domínio desse tipo de configuração textual e dos recursos lingüístico-expressivos mobilizados no texto. Retoma sentidos, realiza inferências, recria o omitido, veiculando-os em seus modos de cultura de linguagem.

O outro sujeito da pesquisa, D., atualiza a história em dois parágrafos, apresentando o problema de Vera de forma enxuta. (Vera era uma vaca que não tinha leite.).

Retoma, então, criativamente o comentário da autora (Imagine uma vaca sem leite que drama.). Evoca o sentimento de Vera, interpretando ter depressão, por viver triste (Vera vivia triste.). Na mesma linha, apresenta seu Manoel como fazendeiro - talvez interpretando ser ele o dono da vaca, e, portanto, que possuísse gado, em uma fazenda. Evoca sua atitude em relação à Vera, com a utilização da perífrase verbal iniciada pelo auxiliar decidir, caracterizando “...uma situação que marcha para o ponto terminal”. (Travaglia, 1985, p. 72), introduzindo o boi Barrica, na tentativa de resolução do problema de Vera (Sen Manuel o fazendeiro decidiu afastar o baldinho de Vera e para alegrar Vera o boi Barriqua fez a festa chamada "bumba-meu-boi".). D. nomeia a festa e o 
faz numa operação concisa, usando oração reduzida. Não fica clara, no entanto, a conexão entre seu Manoel e o boi. O uso de aspas talvez seja pelo fato de nomear o tipo de festa, talvez para enfatizá-la...

No parágrafo seguinte, ela apresenta o acontecimento notável, iniciado por circunstancialização espacial, de forma semelhante a R., apresentando e descrevendo o boi, quase literalmente em relação ao texto original, mas substituindo/deslocando o aumentativo boizão por boižerrão, quiçá pela proximidade de outra palavra manifestada gramaticalmente no aumentativo, ao final texto-fonte - bezerrão (Na festa Vera conheceu um boizerrão muito gato.). A seguir, introduz a oração equivocadamente, por que, ao invés do coesivo marcador de conjunção argumentativa $e$, utilizando perífrases verbais incoativas, iniciadas por começar, para produzir o efeito de urgência temporal e transformação. Também coloca o ápice do acontecimento notável, por meio do operador/circunstancializador até (Que logo começaram a dançar, a se beijar até fazer bezerrinho.).

D. produz o desfecho da história, inferindo, como R., a felicidade das personagens principais, pelo nascimento do filho - ser feliz, ficar feliz faz parte do final canônico das histórias. Usa evocação de sentimento, com uma oração reduzida circunstancializadora, permeada por oração adjetiva, que nomeia o bezerro (Ao o bezerrinho que se chamaria Lucas nascer Vera e Zebu ficaram felizes.) Embora truncado, o período indica o esforço, na tentativa de combinar vários modos de dizer: apresentação de evento, com circunstancialização temporal; a nomeação e a evocação de sentimento. Termina acrescentando, então, as conseqüências do evento final, usando também o pretérito imperfeito (e Vera tinha leite para amamentar Lucas e sobrar para o baldinho de seu Manuel.).

A análise em foco demonstra que esse sujeito coloca-se no mundo da ficção, ao elaborar a leitura/produção desse texto, dominando o processo de arranjo textual, co-enunciando, com seus modos de dizer, sentidos ensejados pela mobilização de elementos lingüísticos e extralingüísticos. 


\section{Os insucessos de leitura}

O texto Dia D - certamente alusão ao dia da invasão da Normandia por tropas aliadas, na Segunda Guerra Mundial, retomado como dia decisivo, marcado, combinado... - da mesma autora de Vera Vaca, possui uma configuração narrativa mais complexa que a usual. Apresenta personagens genéricos e suas falas; encaminha o leitor para a deflagração do conflito - a guerra - que é desdobrado - a batalha; introduz uma personagem específica, Nélio - sem explicitar a que turma ele pertence; descreve o acontecimento notável - o desenrolar do conflito -, seu desfecho e a apresentação de nova complicação, permeada por comentários da autora. No final da história - resolução do último conflito - aparece a conexão entre a personagem Nélio e a turma perdedora. O desfecho é atravessado por discurso direto, manifestado por personagem não identificada, e por nova avaliação.

Para efeito comparativo, subdividimos o texto em oito organizadores dominantes:

- apresentação de personagens genéricos e de suas atitudes usuais;

- introdução do conflito;

- o desdobramento do conflito;

- a apresentação de uma personagem específica; a evocação de sua atitude e sentimento;

- o acontecimento notável (Dia D);

- a resolução da complicação;

- a apresentação de novo conflito;

- a resolução deste conflito e o comentário final. 


\begin{tabular}{|c|c|c|}
\hline TEXTO-FONTE & TEXTO DE R. & TEXTO DE D. \\
\hline $\begin{array}{l}\text { Eram meninos sapecas: os da } \\
\text { rua de cima e os da rua de } \\
\text { baixo. Quando os da rua de } \\
\text { baixo ousavam ir para a rua de } \\
\text { cima, os da rua de cima } \\
\text { gritavam: "Alto lá! Território } \\
\text { inimigo!" O mesmo acontecia } \\
\text { com os da outra rua. }\end{array}$ & $\begin{array}{l}\text { Era uma vez, um menino } \\
\text { sapeca da rua de cima e da rua } \\
\text { de baixo. } \\
\text { Quando eles, usavam ir a } \\
\text { guerra. Lá no território } \\
\text { inimigo. No mesmo } \\
\text { aconteceria da outra rua. } \\
\end{array}$ & $\begin{array}{l}\text { Eram meninos sapecas, os da } \\
\text { rua de cima e os outros da rua } \\
\text { de baixo. } \\
\text { Um dia os da rua de baixo } \\
\text { decidiram invadir a rua de } \\
\text { cima. Alto lá, território } \\
\text { particular! Disse um dos } \\
\text { meninos da rua de cima. } \\
\end{array}$ \\
\hline $\begin{array}{l}\text { Por causa disso, foi declarada } \\
\text { uma guerra. }\end{array}$ & E a guerra foi declarada. & \\
\hline $\begin{array}{l}\text { A primeira batalha foi } \\
\text { marcada para logo depois da } \\
\text { aula. }\end{array}$ & & $\begin{array}{l}\text { Por causa disso eles marcaram } \\
\text { uma batalha, os meninos da } \\
\text { rua de cima contra os da rua } \\
\text { de baixo, logo depois da aula. }\end{array}$ \\
\hline $\begin{array}{l}\text { Nélio, um dos meninos, } \\
\text { chegou a tirar zero em } \\
\text { matemática estava tão } \\
\text { preocupado em armazenar o } \\
\text { caroços de jabuticaba que ia } \\
\text { usar como arma. }\end{array}$ & $\begin{array}{l}\text { Nelio chegou a tirar zero na } \\
\text { prova de matemática. }\end{array}$ & $\begin{array}{l}\text { Hélio por causa da batalha, } \\
\text { tirou zero na prova de } \\
\text { matemática, pensando nos } \\
\text { caroços de jabuticaba para a } \\
\text { batalha. }\end{array}$ \\
\hline $\begin{array}{l}\text { A hora D chegou e, armados } \\
\text { com seus caroços, eles } \\
\text { esperaram o sinal, um pum do } \\
\text { gordo Oscar. }\end{array}$ & & $\begin{array}{l}\text { Então chegou a hora, só } \\
\text { faltava o sinal de Oscar; então } \\
\text { Oscar deu um pum. E } \\
\text { começaram. }\end{array}$ \\
\hline $\begin{array}{l}\text { A batalha terminou quando } \\
\text { acabou a munição de caroços } \\
\text { do pessoal da rua de cima. }\end{array}$ & & $\begin{array}{l}\text { a equipe da rua de baixo } \\
\text { ganhou. }\end{array}$ \\
\hline $\begin{array}{l}\text { Foi aí que eles perceberam } \\
\text { que não tinham levado a } \\
\text { bandeira branca para pedir } \\
\text { trégua ou paz tanto faz! }\end{array}$ & & $\begin{array}{l}\text { e nem pensaram em nenhum } \\
\text { momento em levantar a } \\
\text { bandeira branca. }\end{array}$ \\
\hline \multirow{2}{*}{$\begin{array}{l}\text { Alguém teve a idéia "Vamos } \\
\text { ver quem tem a bunda mais } \\
\text { branca, e quem tiver mostra". } \\
\text { Nélio, coitado, foi o escollido. } \\
\text { E naquele dia, além do zero, ele } \\
\text { ganhou uma cusparada } \\
\text { certeira bem ardida na traseira. } \\
\text { Até agora está doendo. }\end{array}$} & & \\
\hline & $\begin{array}{l}\text { E Nelio levou uma certeira, na } \\
\text { trazeira. E ainda está doendo. }\end{array}$ & $\begin{array}{l}\text { Hélio levou tantos caroços na } \\
\text { bunda que até hoje está } \\
\text { doendo. }\end{array}$ \\
\hline
\end{tabular}

SIGNUM: Estud. Ling., Londrina, n. 5, p. 239-254, dez. 2002 
R. inicia a apresentação das personagens, de forma canônica. Mas ele as apresenta como um menino sapeca da rua de cima e da rua de baixo. Retomaas por eles e, de forma confusa, tenta falar da iminência da guerra entre os grupos (Era uma vez, um menino sapeca da rua de cima e da rua de baixo. Quando eles, usavam ir a guerra. La no território inimigo. No mesmo aconteceria da outra rua.).

O conflito - a declaração de guerra - é explicitado e a personagem Nélio, por meio da evocação de uma atitude, é introduzida sem conexão com o restante da história (e a guerra foi declarada Nelio chegou a tirar zero na prova de matemática). Apresenta, então, incoerentemente, através da personagem citada, parte do final da história e o comentário original, com pequenas modificações (E Nelio levou uma certeira, na trazeira. E ainda está doendo.).

Pode-se afirmar, dessa forma, que a dificuldade na leitura/ (co) produção da história Dia D, no caso de R., relaciona-se a problemas de competência lingüístico-textual e de conhecimento de mundo: à maior complexidade configurativa deste texto em relação à Vera Vaca; à não distinção de sentidos entre os termos guerra e batalha; à não recuperação de significado da expressão Dia D (como dia decisivo, acontecimento notável) e de bandeira branca no texto; inclusive, ao desconhecimento do termo ousar, que ele lê/interpreta como usar. Elementos somados que, desconhecidos de seu universo sócio-lingüístico-cultural, levaram-no ao insucesso de leitura.

O outro sujeito, D., no início de sua história, composto por três parágrafos, apresenta os dois grupos de personagens, de forma semelhante à autora. No entanto, o que era costumeiro e recíproco no texto-fonte a invasão do território inimigo - é apreendido como, apenas, a invasão, que ocorrera pontualmente, de um grupo no território de outro e, então, motivo para a existência do conflito, que ela subsume como batalha (Eram meninos sapecas, os da rua de cima e os da rua de baixo./ Um dia os da rua de baixo decidiram invadir a rua de cima. Alto lá, território particular disse um dos meninos da rua de cima. / Por causa disso eles marcaram a batalha, os meninos da rua de cima 
contra os da rua de baixo, logo depois da aula.). Verifica-se que, em 3 parágrafos, D. modifica a organização dos modos de dizer do texto original: apresenta as personagens, topicalizando e individualizando atitudes que eram freqüentes e recíprocas; explicita a conseqüência das atitudes, paralelamente introdu₹indo o conflito. Ainda, ao colocar o elemento causador da complicação, retomamodifica o discurso direto, mas atribuindo-os aos meninos da rua de cima. A fala aparece sem aspas e com verbo de elocução diz̧er posposto, em substituição a gritar. Ousavam ir é inferido como decidiram invadir. Nota-se, ainda, a mudança do tempo: o que era habitual tornou-se pontual (perfectivo). O movimento lexical executado demonstra a transposição do sentido apreendido para expressão de termos próprios de seus modos de cultura de linguagem. D. utiliza a perífrase verbal decidir + verbo no infinito, significando situação em marcha que caminha para seu fim, conforme já exposto.

Introduz a personagem Nélio, nome certamente desconhecido de seu repertório cultural, retomada por Hélio, com evocação de suas atitudes e preocupaçoes, justificando-as (Hélio por causa da batalha, tirou zero na prova de matemática pensando nos caroços de jabuticaba para a batalha.). Emprega o gerúndio, para demonstrar a duração de ansiedade de Nélio, retomando-modificando preocupar-se por pensar.

Num movimento textual criativo, coloca o momento do conflito e faz uma ressalva - que funciona como pano de fundo da história - para apresentar o detonador do início da batalha (Então chegou a hora so faltava o sinal de Oscar; então Oscar deu um pum). Observa-se que D. apresenta a personagem Oscar, na sua graça e importância, porém, não descreve/ compõe a personagem como gordo, tal qual é feito no texto original.

O conflito realmente acontece no início do próximo enunciado, no qual ela coloca também a resolução do mesmo e a apresentação de nova complicaşão (E comecaram a equipe da rua de baixo ganhou, e nem pensaram em nenhum momento, em levantar a bandeira branca.). Retoma pessoal por equipe. Embora não mencione o fim das munições, deve ter inferido que, se acabou a 
munição do pessoal da rua de cima, o da rua de baixo ganhou. A partir daí, talvez por não apreender o significado de bandeira branca como pedido de paz, como capitulação, relaciona-a à turma vencedora e por isso sua leitura é prejudicada. Nélio ainda reaparece no final da história sem conexão com a necessidade de suprimento do símbolo de trégua. (Hélio levou tantos caroços na bunda que até hoje esta doendo.). É provável que, por não inferi-lo como perdedor e estandarte da derrota, D. não tenha memorizado as cusparadas que ele levara, modificando-as pelas armas dos meninos: os carogos de jaboticaba.

Observa-se que o arranjo textual de Dia D também prejudicou a leitura desse sujeito. Embora omitindo/confundindo a reciprocidade de ações dos grupos, ela tem um relativo sucesso como leitora até o momento da resolução do segundo conflito. A partir daí, a complexidade textual e o desconhecimento do significado de bandeira branca, que, possivelmente, não faça parte de seu universo lingüístico-cultural, provocam uma grande lacuna em sua co-produção, de sentidos, na conclusão desconectada da parte anterior de sua história.

Nesse sentido, a configuração textual parece ter sido a maior causadora do insucesso da leitura de R. e do pouco sucesso da leitura de D.. Concorre, ainda, para outra grande dificuldade da leitura dos mesmos, a existência da expressão bandeira branca que não deve fazer parte dos sentidos veiculados nos modos de cultura de linguagem de ambos.

\section{À guisa de conclusão: e a escola, como fica?...}

Nos êxitos e insucessos de leituras, apontados na reconstrução da caminhada interpretativa dos sujeitos em foco, buscou-se apresentar suas marcas individuais - conhecimentos lingüísticos, textuais e de mundo no processo de co-produção de sentidos de textos narrativos escritos, gênero supostamente veiculado pela (na) escola, desde os primórdios da educação formal. 
No entanto, conforme observado, somente o primeiro texto, com arranjo e vocábulos mais usuais, logrou êxito junto aos leitores da pesquisa, possibilitando-lhes a mobilização de aspectos verbais e não verbais, na co-enunciação de sentidos. A segunda narrativa, certamente, exigiu dos alunos transações lingüísticas e não lingüísticas que não fazem parte de seus modos de cultura de linguagem, embora eles apresentem, ao menos, cinco anos de escolaridade.

Ainda que não exaustivos, esses dados levam à reflexão sobre o papel da escola pública na constituição e ampliação da subjetividade, como produtora de sentidos, para as camadas populares.

Nesse contexto, talvez único horizonte de alargamento de representação/concepção de mundo, de universo discursivo disponível a essa clientela, configura-se a real necessidade de se criar um espaço interlocutivo em que as leituras sejam externadas e confrontadas, levandose em conta a relação do texto com a história de vida e de leitura dos alunos.

É no trabalho mediador entre o sujeito (leitor em processo de aprendizagem) e a leitura (objeto de estudo) que as capacidades de retomada-modificação são privilegiadas. É fruto desse ambiente interativo a descoberta do porquê da construção de certos sentidos, e de outros não, pelos leitores.

\section{Referências bibliográficas}

BRANDÃO, Helena N. Escrita, leitura e dralogicidade. In: BRAIT, B. (Org.). Bakbtin, dialogismo e construção de sentido. Campinas: Editora da UNICAMP, 1997. p. 281-288.

DELL'ISOLA, Regina L.P. A interação sujeito-linguagem em leitura. In: MAGALHÃES, I. (Org.). As múltiplas faces da leitura. Brasília: Editora da UNB, 1996. p. 69-75. 
ECO, Umberto. Interpretação e sobreinterpretação. Trad. de M.S. Pereira. Lisboa: Presença. 1993.

FRATE, Diléa. Histórias para acordar. São Paulo: Companhia das Letrinhas, 1996.

GERALDI, João W. Portos de passagem. São Paulo: Martins Fontes, 1991.

MESERANI, Samir. O intertexto escolar: sobre leitura, aula e redação. São Paulo: Cortez, 1995.

PERFEITO, Alba M. Leitura e produção de textos: maneiras de ver, maneiras de dizer... 1999. Tese (Doutorado) - Faculdade de Filosofia, Letras e Ciências Humanas - Universidade de São Paulo, São Paulo.

POSSENTI, Sírio. A leitura errada existe. In: GRUPO DOS ESTUDOS LINGÜÍSTICOS, 30, Franca. UNIFRAN, 1990. Anais... Franca: 1991. p. 717-724.

TRAVAGLIA, Luiz C. O aspecto verbal no português: a categoria e sua expressão. ed. rev. Uberlândia: Universidade Federal de Uberlândia, 1985. 